\title{
What is the Controllable Electrical Demand from Non-Residential Electric Vehicle Supply Equipment in the San Diego Region?
}

Idaho National Laboratory

December 2015

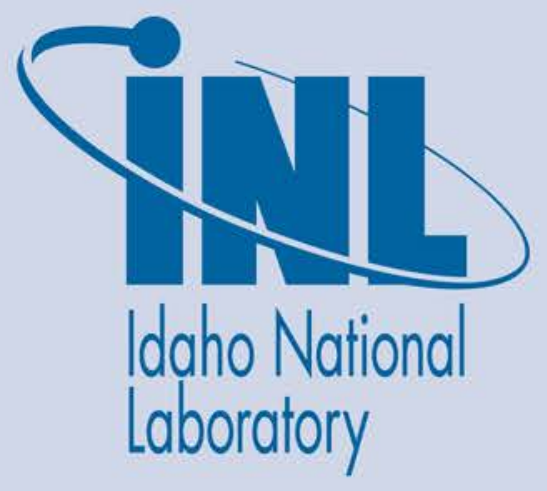

The INL is a U.S. Department of Energy National Laboratory operated by Battelle Energy Alliance 
INL/EXT-15-36321

\section{What is the Controllable Electrical Demand from Non-Residential Electric Vehicle Supply Equipment in the San Diego Region?}

Idaho National Laboratory

December 2015

Idaho National Laboratory

Idaho Falls, Idaho 83415

http://www.inl.gov

Prepared for the

U.S. Department of Energy

Assistant Secretary for _ , OR Office of

Under DOE Idaho Operations Office

Contract DE-AC07-05ID14517 


\section{=VProject}

\section{What is the Controllable Electrical Demand from Non-Residential Electric Vehicle Supply Equipment in the San Diego Region?}

December 2015

\section{Key Conclusions}

- The aggregated EV Project non-residential electric vehicle supply equipment (EVSE) charging demand in San Diego did not exceed $100 \mathrm{~kW}$ at any time during the third quarter of 2013. $100 \mathrm{~kW}$ is typically the minimum aggregated demand useful in demand response actions.

- The aggregated utilization, in an electric utility service territory, of private non-residential EVSE used for fleet and workplace applications is not likely to provide $100 \mathrm{~kW}$ of aggregated demand for a significant time.

- The aggregated utilization of publicly accessible EVSE would need to increase by a factor of four in order to provide significant demand for utility demand response actions during the period of highest total grid load during The EV Project for San Diego Gas and Electric (SDG\&E).

- The pool of publicly accessible EVSE, along with the pool of PEVs parked near (i.e., within $300 \mathrm{ft}$ ) of these EVSE, which could potentially connect to them for charging, are currently of sufficient size in the San Diego region of The EV Project to make demand response actions possible.

- The proper incentive program promoted by SDG\&E through rate design, coupled with smart EVSE, may be sufficient to accomplish connectivity sufficient for demand response.

- For the foreseeable future, direct utility control of non-residential EVSE is not beneficial, whereas indirect control through rate structures continues to be effective.

\section{Introduction}

The EVSE deployed by The EV Project included both residential and non-residential units. Approximately 4,000 non-residential alternating current (AC) Level 2 EVSE were installed in workplace environments, fleet applications, and publicly accessible locations near retail centers, parking lots, and similar locations. The power required to recharge a plug-in electric vehicle (PEV) can be a significant additional electrical load to electric grid, but may also provide a controllable resource for mitigating grid overload issues.

Electric utilities seek ways to reduce their generating costs by controlling the maximum (i.e., peak) load on their system, their generating resources, and frequency and voltage control on the system. This management may be achieved indirectly through rates that incentivize their customers (including PEV owners) to manage the charging of their vehicles or may take the form of direct utility control of non-residential EVSE. What insight can The EV Project data provide related to the magnitude of this impact and the potential controllable demand? The paper titled, "What is the Controllable Electrical Demand from Residential Electric Vehicle Supply Equipment in the San Diego Region?"1 addressed this question for residential EVSE. This paper quantifies the total controllable electrical load imposed on the electric grid by non-residential PEV charging in the San Diego region of The EV Project.

\section{Why is Controllable Demand Important?}

The electric utility is responsible for providing power to customers within its service territory. SDG\&E is solely responsible for providing electricity for all customers within the San Diego region of The EV Project. SDG\&E publishes its dynamic load profile that shows the power required by its customers during a specific period of time. The profile for the third quarter of 2014 is shown in Figure 1.

The total power demanded by SDG\&E customers for each hour of the day is plotted in Figure 1, showing the maximum, median, and minimum power demanded over the 3-month period for each hour of the day.

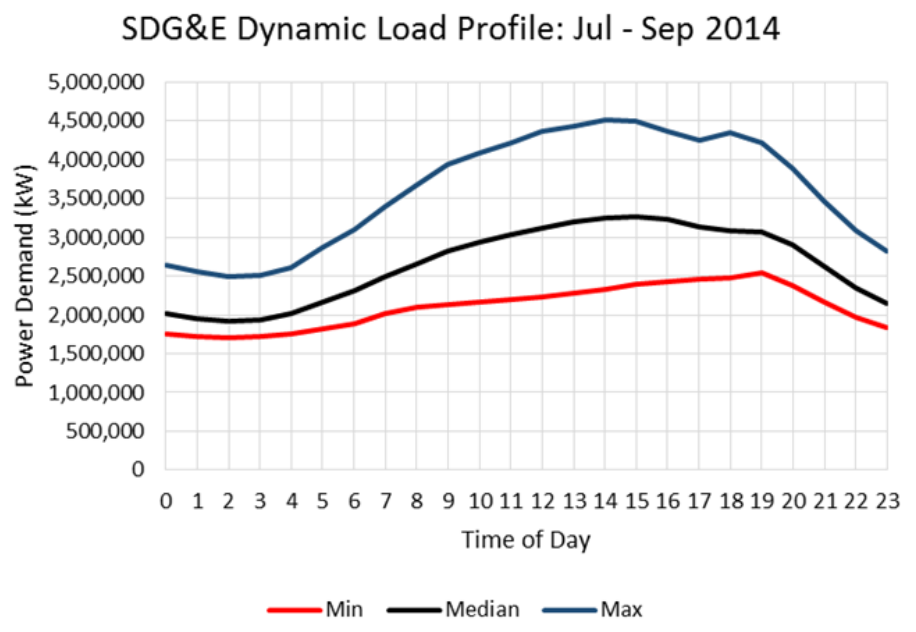

Figure 1. SDG\&E hourly demand. ${ }^{2}$

SDG\&E must generate and provide power to match the power demand, which, during this 3-month period, varied 
from a minimum of 1,920 to $3,269 \mathrm{MW}$ in the median value. Generation is provided by first operating "base-load" generation. These base load power plants are generally the least expensive generating units to operate and are most efficient when operating at full power. These units are typically fully loaded to provide power all day. Once this base-load capability is fully utilized, other generating plants are brought into service. The last plants to be utilized are "intermediate" and "peaking" units, that are more expensive to operate and whose output can be modulated more rapidly. Therefore they are only used when necessary to handle the peak loads. In some situations, utilities may need to purchase power from other sources to fulfill peak load requirements. If the utility can shift the peak power demand to other times, the cost of operating peaking power plans and purchasing power from other utilities during peaks can be avoided.

In anticipation of power demand increases or problems on the grid causing a reduction in power generation, utilities typically operate "spinning reserve" generation. These are generating stations that are fully operational and, although not loaded, are fully prepared to rapidly supply power to the grid in order to "follow" the demand or to make up for a sudden loss of generating resources. During transitional increases or decreases in demand, these spinning reserves may cycle on and off. If the demand can be controlled, this cycling may be avoided and the reserve unit operated in a more stable state.

In addition to managing the total power generation to match the demand, the electric grid must maintain the voltage and frequency. This regulation can be achieved by controlling small amounts of generation, or conversely by controlling small amounts of load - the power demanded by customers on the electric grid.

Figure 2 illustrates these three major situations. Controlling the demand, even in some minimal amounts, in these three areas helps the electric utility to reduce costs.

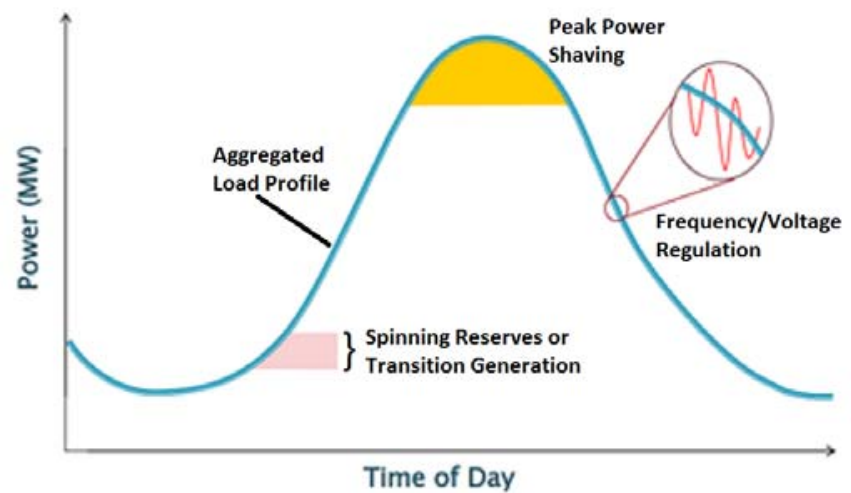

Figure 1. Controllable demand situations
The electric utility has several tools available to assist in managing its power demand requirements. For this paper, controlling the demand from non-residential PEV charging is of interest. The approach then is to determine the effectiveness of controlling non-residential EVSE demand to reduce the overall peak load, assist in the transition loading and unloading generation, or in frequency and voltage regulation. In general, the first two require substantial controllable load, since the overall load curve involves thousands of megawatts. However, frequency and voltage regulation can be accomplished through cycling on or off relatively small loads.

\section{Controlling Demand}

To be useful in controlling demand, a minimum of $100 \mathrm{~kW}$ of controllable power is generally required. This would require aggregating many EVSE that are connected to vehicles where both the vehicle and EVSE are available for charging. Because there are financial incentives for providing this demand control, there are frequently penalties for failing to provide the adequate control. Thus, this system will require:

- EVSE or PEVs capable of remote control and monitoring

- Aggregation systems and programs

- Sufficient numbers of EVSE with a PEV connected and charging to provide demand for aggregation

- Communication signals from the utility to the aggregator of service

- Enlistment and communications methods to participating EVSE owners and PEV drivers

Smart EVSE that allow for monitoring and control and communication through the Internet, such as the Blink unit deployed in The EV Project, are capable of aggregation. Demonstrations of controllable demand from utility through EVSE have occurred in several forms including that conducted by California Energy Commission grant ARV-09005 involving SDG\&E ${ }^{3}$.

Control of demand may include starting and stopping charging, regulating the rate of charging, or in some cases, discharging the PEV battery through the EVSE back to the grid. The later example, called vehicle-to-grid or V2G, requires additional PEV features, and is an advanced capability, currently being tested, but not the focus of this paper. For this paper, only the curtailment or restoration of charging, frequently called V1G, is of interest.

The condition that remains to be addressed here is whether there are sufficient numbers of EVSE with connected 
vehicles for aggregation to provide the required $100 \mathrm{~kW}$ of controllable demand.

\section{Data Analyzed}

The EV Project published reports on a quarterly basis on specific aggregated data points. Electric utilities within the boundaries of The EV Project requested specific information related to the demand and energy requirements for charging of PEVs. These reports are available at avt.inl.gov/evproject.shtml. Information from these quarterly reports was analyzed for this report. The EV Project collected charge data from the Blink EVSE it deployed. Data from those AC Level2 EVSE installed in non-residential locations were also analyzed for this report.

The paper titled, "Characterize the Demand and Energy Characteristics of Non-residential Alternating Current Level 2 Electric Vehicle Supply Equipment," identified common characteristics of the power and energy consumed by PEV charging at non-residential EVSE and expected times and durations of the charge periods. That paper generalized the information over many regional markets of The EV Project. This paper continues the case study of San Diego to identify the specific controllable demand for this one region. The principles discussed herein could be applied to all regions of the United States where a sufficient PEV population exists.

The charge rate and, therefore, the demand for energy to recharge the battery are determined by the PEV's onboard battery management system. The Blink AC Level 2 EVSE provided to The EV Project's charging site host is capable of delivering up to $7.2 \mathrm{~kW}$ power to a connected PEV. The project charge data show that most PEVs participating in The EV Project charged at $3.76 \mathrm{~kW}$ or less. However, some PEVs deployed late in The EV Project did charge at up to $7.2 \mathrm{~kW}$. This information is useful in understanding the potential non-residential EVSE demand effects.

\section{Non-Residential Electric Vehicle Supply Equipment Controllable Demand}

Non-residential EVSE include EVSE installed for fleet and workplace environments and those that are publicly accessible. The fleet and workplace EVSE, collectively termed in The EV Project's quarterly reports as "private non-residential," have the capability to control times that charging takes place. Informed business owners may take advantage of this capability to reduce their electrical costs. The publicly accessible EVSE, on the other hand, are operated when the visiting PEV driver plugs in and desires a charge, which can occur at any time of the day. The demand control aspects of these two classifications of non-residential EVSE are discussed separately herein.

\section{Private Non-Residential Electric Vehicle Supply Equipment}

The EV Project's quarterly report for the third quarter of 2013 provided the weekday charging availability and charging demand curves shown in Figures 3 and 4.

Charging availability is defined as the percent of EVSE that have a PEV connected in a geographical area. This is calculated by aggregating the data generated from all Blink EVSE built-in electric meters in the group of EVSEs being evaluated, in the geographic area of interest, over the timeframe desired.

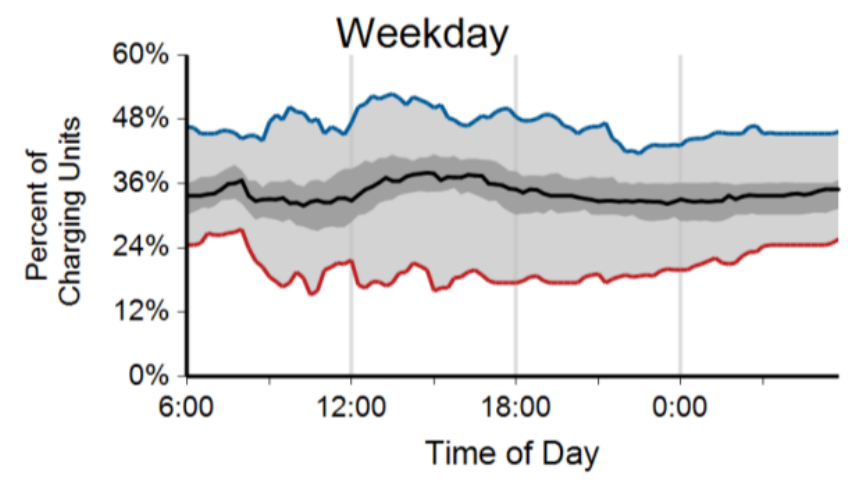

Figure 3. San Diego private non-residential EVSE weekday charging availability for the third quarter of 2013.

Charging demand is defined as the total amount of power being drawn from the electric grid by a group of EVSE in a geographical area. This is calculated by aggregating the charge data generated from all the Blink EVSE built-in electric meters in the area of interest over the timeframe desired.

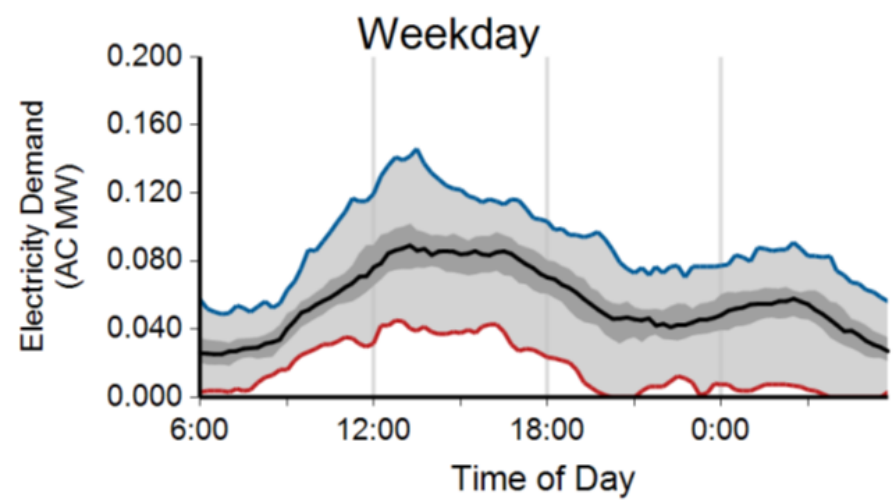

Figure 4. San Diego private non-residential EVSE weekday charging demand in San Diego for the third quarter of 2013.

In these graphics, the demand for each day of the quarter is overlaid on the time of day; therefore, the upper blue line 
indicates the maximum availability or demand over the quarter, the red line shows the minimum values, and the black line shows the median availability and demand over the quarter. The inner quartiles are shown as gray-shaded areas and provide information on how closely the data aggregates to the median value. The data for weekdays and weekends are graphed separately.

For example, using the median values, at noon on weekdays during the third quarter of $2013,33 \%$ of all EV Project installed private non-residential Blink EVSE were connected to a PEV and the electrical demand at that time was $0.076 \mathrm{AC}$ megawatts (MW).

Figure 3 shows that a fairly consistent and steady percentage of these EVSE are connected to PEVs throughout the day. A slight increase in the percentage of connected PEVs occurs in the mid-afternoon period.

Figure 4 shows that, although the percentage of EVSE in use is fairly constant throughout the day, the majority of vehicle charging occurs in the mid-afternoon period that corresponds to the time of the increase in EVSEs connected to PEVs. The increase in charging demand after 10 p.m. appears to be influenced by the SDG\&E electric rate schedule.

\section{Time of Use}

Through the use of rate incentives, such as time-of-use, customers are encouraged to shift their power demand to semi or off-peak times. The SDG\&E Time-of-Use- $A^{5}$ rate schedule is for non-residential customers whose maximum monthly demand equals or exceeds $20 \mathrm{~kW}$. Most fleet or workplace businesses would be expected to be on this rate. It identifies separate rates for summer and winter. The summer rates apply for the third quarter and are identified in Table 1.

Table 1. SDG\&E summer time periods.

\begin{tabular}{|c|c|c|}
\hline On-Peak & 11 a.m. -6 p.m. & Weekdays \\
\hline Semi-Peak & 6 a.m. -11 a.m. & Weekdays \\
\hline Off-Peak & 10 p.m. -6 a.m. & $\begin{array}{l}\text { Weekdays, } \\
\text { Weekends, and } \\
\text { Holidays }\end{array}$ \\
\hline
\end{tabular}

Thus, fleet vehicles may be programmed to commence charging after 10 p.m. in order to take advantage of reduced electrical rates.

Figure 4 also shows a significant amount of charging demand during the on-peak times, which indicates that either the incentives are not sufficient to change charging behavior or the nature of the business is such that charging cannot be delayed.
The minimum electricity demand from Figure 4 during on-peak times is $0.024 \mathrm{MW}$ at $6 \mathrm{p} . \mathrm{m}$. This compares to the median load profile of 3,129 MW for SDG\&E in Figure 1. Curtailing this private non-residential load would have negligible impact on the overall load profile, nor would it have any meaningful impact on the transition generation of Figure 2. Thus, frequency and voltage regulation using private non-residential EVSE may be the only option for utility benefit.

\section{Utility Control of Private Non-Residential Plug-In Electric Vehicle Charging}

Controllable demand from EVSE requires the EVSE to be connected to and charging the PEV. Unless the EVSE is actually charging the PEV (i.e., putting an electrical load on the grid), there is no demand to curtail or control. A fully charged PEV provides no opportunity for control through load shedding.

It was noted above that controllable demand usually involves providing at least $100 \mathrm{~kW}$ of controllable power. Because of the penalties for failure to deliver, the minimum available demand over the quarter is used in this analysis. Figure 4 shows significant time periods throughout the day where the median power demand is zero, or near zero, and at no time during the quarter did the median power demand exceed $100 \mathrm{~kW}$.

Because current rate incentives have not been able to shift significant charging to off-peak, it is unlikely the businesses would relinquish control of charging to a third party for use in controllable demand. A significant increase in the population of EVSE and PEVs in fleets or the workplace would be necessary for this to be a viable option for supporting load management.

\section{Publicly Accessible Electric Vehicle Supply Equipment}

The EV Project quarterly report for the third quarter of 2013 provided the weekday charging availability and charging demand curves shown in Figures 5 and 6 .

The shape of the curves in Figures 5 and 6 are similar, indicating that for publicly accessible EVSE, PEVs commence the charge immediately upon connecting to the EVSE. This would be expected in publicly accessible EVSE that are located at driver destinations such as shopping centers or entertainment venues. The PEV driver expects the charge to occur while visiting the venue and disconnects upon return to the vehicle.

In the current situation, it is assumed the PEV drivers connect because they need or desire the charge. For publicly accessible EVSE involved in any demand response actions, PEV drivers would need to be willing to 
connect without necessarily receiving a charge. This would include the PEV drivers who may not need the charge when they connect or other PEV drivers who may park in the vicinity of the EVSE but would not normally connect. An incentive may prompt them to connect even though they may not otherwise do so.

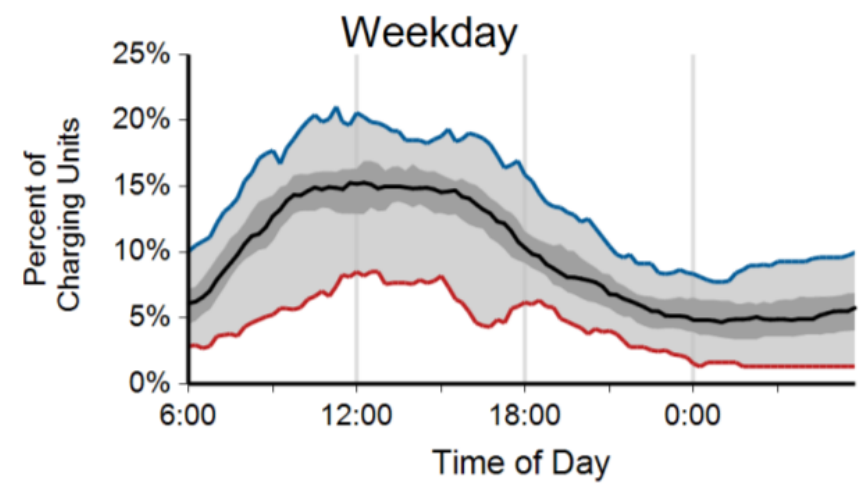

Figure 5. San Diego publicly accessible EVSE weekday charging availability for the third quarter of 2013.

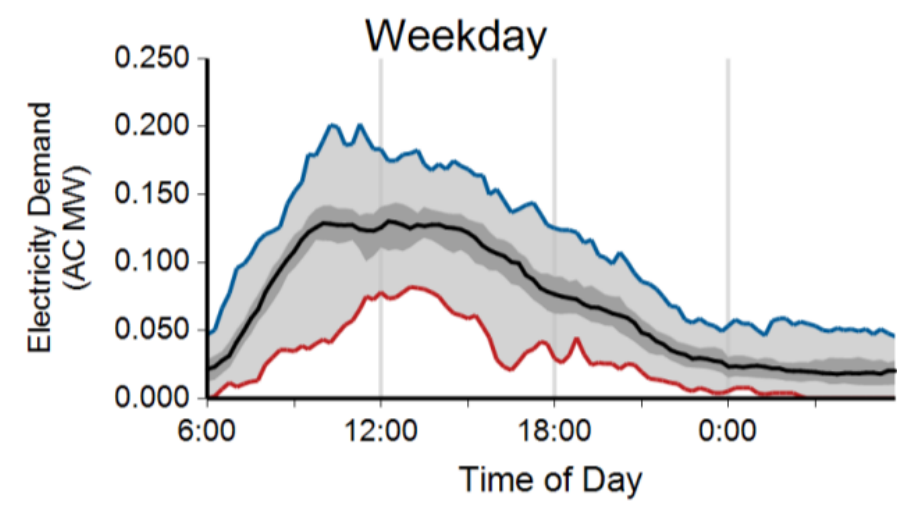

Figure 6. San Diego publicly accessible EVSE weekday charging demand in San Diego for the third quarter of 2013.

The paper titled, "Do Plug-In Electric Vehicle Drivers Park Near Publicly Accessible Electric Vehicle Supply

Equipment in San Diego but Not Use Them?"6 reported an average of $26 \%$ of The EV Project PEVs that parked near (i.e., within $300 \mathrm{ft}$ ) an EVSE site installed by The EV Project actually charged at that site. It also reported that the probability of a PEV charging if it parks near (i.e., within $300 \mathrm{ft}$ ) of an EVSE is approximately 1 in 4 regardless of the frequency of PEVs parking in the area and regardless of the venue. Therefore, on average, $75 \%$ of PEVs that park near a publicly accessible EVSE do not use it, but easily could if it were available since they are within $300 \mathrm{ft}$ of that site. While the vehicles that are connected may or may not actually need the charge, the vehicles not connected obviously do not. However, they can become part of a pool of vehicles that could connect to be available for controllable demand activities, should there be incentives for doing so.

\section{Connect Time and Charge Time}

PEVs connected to EVSE, but not charging, offer no opportunity for demand control and actually block any other PEV from charging and participating in demand control. Therefore, maintaining short idle times is desirable in a demand control scenario. To evaluate connect time versus charge time, the Blink quarterly data from The EV Project was investigated. Charge events of greater than 24 hours or from EVSE at known private non-residential venues were eliminated.

Plug connect and disconnect times were used to identify the connect time for each plug-in event. For those same events, the charge start and stop times were used to identify the charge time. Subtracting the charge time from the connect time yields the idle time (i.e., the time the PEV remains connected after the charge is completed). The distribution of these idle times is shown in Figure 7.

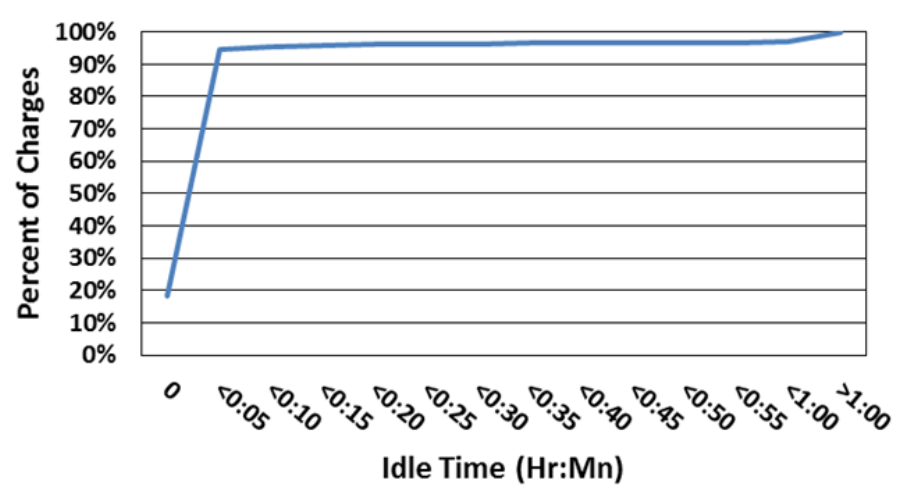

Figure 7. Cumulative distribution of publicly accessible EVSE idle times.

Further, 95\% of the plug-in events have idle times less than 5 minutes. During this quarter, the median connect time was 2 hours, 28 minutes, and 18 seconds. The median idle time was 10 seconds. The average length of plug-in time was 4 hours and 6 minutes. The average length of idle time was 13 minutes. Only $3 \%$ of the plug-in events had idle times exceeding 1 hour. The average energy consumed during the event was $9.4 \mathrm{kWh}$.

During this data period, the publicly accessible fee structure was based on connect time. The PEV driver was incentivized to disconnect from the EVSE immediately upon completing the charge. As expected, this led to short idle times. More recently, many of the PEV charging networks have based fees on energy consumed by the PEV. What effect will this have on connect times?

A disincentive for longer connect times would be a higher fee for more energy consumed. The third quarter of 2013 
report for the Nissan Leaf identifies the away-from-home battery state of charge at the beginning and the end of charge. The average state of charge at the end of charge for the Nissan Leaf is $88 \%$, while the Volt is $86 \%$.

Extending the connect time at the publicly accessible EVSE will, on average, increase the energy consumed but not significantly because the on-board battery management systems will curtail the rate the battery is charging as it nears a full charge. Any incentive for participating in a demand reduction program would have to outweigh the disincentive of the higher energy consumption fee. In addition, any actions taken to curtail the charge would reduce the energy consumption fee. It is also important to note that the batteries of these non-connected vehicles are not fully charged and thus could be used for charging start or stop control.

\section{Controllable Demand at Publicly Accessible Electric Vehicle Supply Equipment}

To improve data quality for analysis purposes, several qualifying factors were placed on the publicly accessible EVSE charge data in the quarterly reports. This resulted in the exclusion of data from some EVSE. In addition, some EVSE, although functional, failed to report data.

In the third quarter of 2013, The EV Project had installed a total of 530 non-residential EVSE in the San Diego region. Further, 334 of the 405 publicly accessible EVSE reported data in the third quarter. This represented $82 \%$ of the installed publicly accessible EVSE.

Figures 5 and 6 present the maximums and minimums in connected chargers (EVSE availability) and charging demand. In evaluating the potential for controllable demand, the minimum values of charging demand would represent a conservative estimate because, at all times, the charging demand is at least as much as these values. Likewise, the maximum percentage of EVSE connected would be a conservative figure because that demand is provided by these or fewer EVSE. Figure 8 shows the minimum curve for energy demand and maximum curve for EVSE connected for the third quarter of 2013.

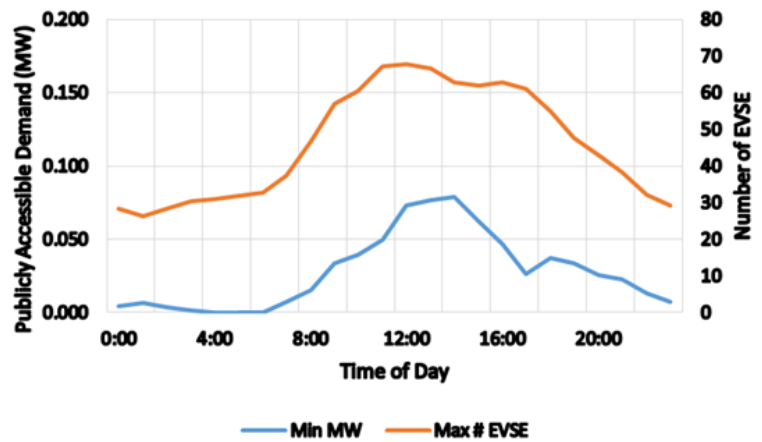

Figure 8. Publicly Accessible EVSE availability and demand for the third quarter of 2013.
According to the third quarter 2013 report, at no time did the minimum aggregated charging demand exceed $100 \mathrm{~kW}$, which is the minimum typically required for bidding into demand response actions. The potential maximum available controllable demand would occur at $0.08 \mathrm{MW}$ $(80 \mathrm{~kW})$ at 2 p.m., when 18\% (i.e., 62) of the EVSE were connected to PEVs.

As noted above, these data were obtained from $82 \%$ of the installed publicly accessible EVSE. Assuming that the balance of the EVSE performed in a similar manner, demand and availability are shown in Figure 9.

Again, at no time did the demand exceed $100 \mathrm{~kW}$. However, with only about $20 \%$ of the available EVSE connected to PEVs, there is opportunity to increase connectivity and demand at the same time.

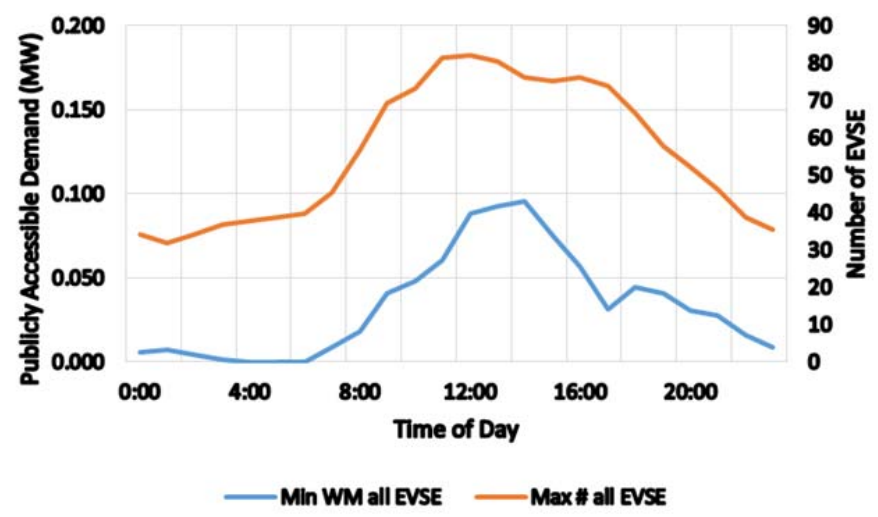

Figure 9. Availability and demand of publicly accessible EVSE - all installed EVSE.

As with private non-residential EVSE, the amount of potential controllable demand is less than $100 \mathrm{~kW}$ and, when compared to the overall load curve of Figure 1 involving thousands of MW, the potential for peak shaving is minimal. Focus for the electric utility may be on transitional generation or more probably on frequency and voltage regulation, particularly in local areas of the grid.

Because the minimum availability of EVSE is zero at various times of the day, it is unlikely that increased incentives will add much to connectivity at those times of the day. Rather the shape of the connected curve is likely to remain the same but incentives could increase the numbers of PEVs connected.

If the number of vehicles connected to these EVSE is increased by a factor of 4 , the resulting curves would be as shown in Figure 10.

In this situation, the available connected demand exceeds $100 \mathrm{~kW}$ from 9 a.m. to 9 p.m., encompassing the on-peak times for SDG\&E and many generation transition periods. 


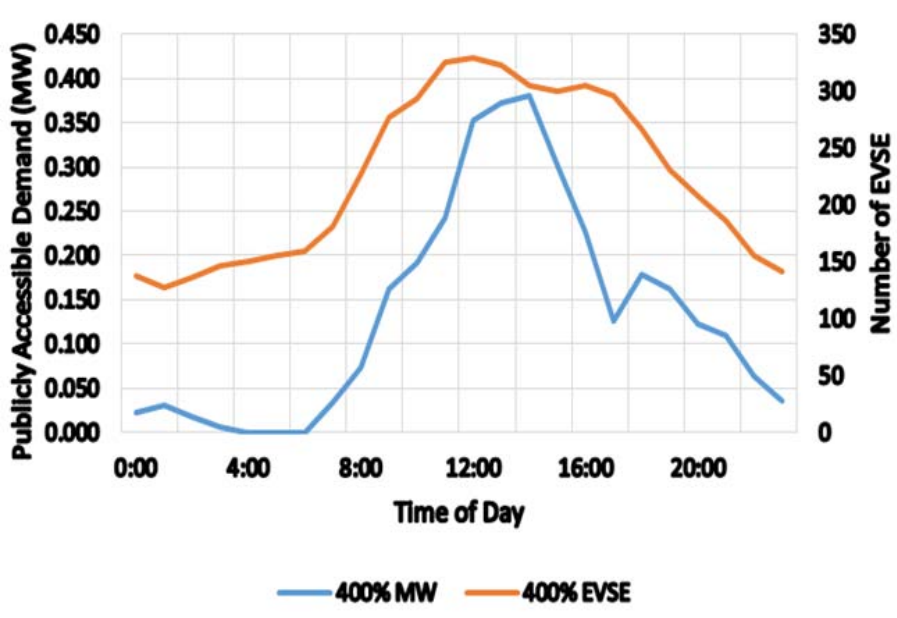

Figure 10. Projected publicly accessible EVSE availability and demand.

A total of 329 publicly accessible EVSE would be connected to PEVs, representing $81 \%$ of The EV Project's installed publicly accessible EVSE. Many additional publicly accessible EVSE have been installed since the conclusion of this project in December 2013; however, smart EVSE capable of aggregation and control would be required. Because there are significant numbers of PEVs parked in the vicinity of these EVSE that are not charging, a source of these connected PEVs is available.

Third party aggregators may find it profitable to enlist the PEV drivers in order to bid specific times for demand response. SDG\&E may elect to manage these services directly using available participants. SDG\&E has already shown success in influencing driver behavior with incentives from the rate structure for residential charging (see "Residential Charging Behavior in Response to Utility Experimental Rates in San Diego"7). With rate incentives and charge control, SDG\&E may be able to aggregate sufficient quantities of EVSE to provide transition generation assistance and frequency and voltage control.

PEV drivers have shown that although they were parked near a publicly accessible EVSE, they did not connect and were assumed to not need a charge. With incentives, they may connect for the benefit of the incentive and take EVSE availability away from a PEV driver that may actually need the charge. Some accommodation would be required to allow a PEV driver to opt out of the incentive if the charge was necessary. The charging site host is usually compensated through fee sharing for providing the services for the connected PEV. If fees are based on energy consumed and demand is curtailed, the host may see reduced revenue. However, as the owner of the EVSE providing the services for control, the host may be included in the incentive program by the utility.

\section{Conclusions}

The EV Project installed 530 non-residential EVSE in the San Diego region by December 2013. These include publicly accessible EVSE and those installed in private non-residential operations such as fleets and the workplace.

At the end of The EV Project, the electrical demand generated by PEVs connected to these non-residential EVSE was insufficient for contributing to overall load management. An increase in the number and utilization of private non-residential EVSE is required for aggregation of these units to be practical in supporting demand control actions. However, current utilization of publicly accessible EVSE suggests aggregation to support these demand control actions may not be that distant. In the third quarter of 2013, at most, $20 \%$ of the installed EVSE were in use.

The balance of these units, plus new smart units installed since then, provides a significant number of EVSE available for PEV connectivity. At the same time, a significant number of PEVs are parked near (i.e., within $300 \mathrm{ft}$ ) of the publicly accessible EVSE, but are not using them. With the proper incentive, the drivers of these PEVs could connect and be available for demand response actions.

The incentive programs promoted by SDG\&E, coupled with easily programmable EVSE, have already demonstrated effectiveness in modifying PEV driver behavior for charging at home. This was accomplished by rate design rather than by aggregating EVSE resources. It is likely that the proper rate design, coupled with smart EVSE, may also incentivize PEV drivers to connect at publicly accessible EVSE and actually charge only when mutually beneficial to the electric utility and the driver.

This minimizes the need for directly controllable demand. However, as the number of residential EVSE continues to grow, there may be benefits to the third-party aggregators or the utility having direct control. This analysis shows that connectivity to publicly accessible EVSE would need to grow by a factor of 4 to make direct control minimally worthwhile at peak hours of the day. For the foreseeable future, direct utility control of non-residential EVSE is not beneficial, whereas indirect control through rate incentives may be beneficial.

\section{About The EV Project}

The EV Project was the largest PEV infrastructure demonstration project in the world, equally funded by the United States Department of Energy (DOE) through the American Recovery and Reinvestment Act and private sector partners. The EV Project deployed over 12,000 AC Level 2 charging stations for residential and commercial 
use and over 100 dual-port direct current fast chargers, in 17 U.S. regions. Approximately 8,300 Nissan Leafs ${ }^{\mathrm{TM}}$, Chevrolet Volts, and Smart ForTwo Electric Drive vehicles were enrolled in the project.

Project participants gave written consent for EV Project researchers to collect and analyze data from their vehicles and/or charging units. Data collected from the vehicles and charging infrastructure represented almost 125 million miles of driving and 4 million charging events. The data collection phase of The EV Project ran from January 1, 2011, through December 31, 2013. Idaho National Laboratory is responsible for analyzing the data and publishing summary reports, technical papers, and lessons learned on vehicle and charging unit use.

\section{Company Profile}

Idaho National Laboratory is one of DOE's 10 multi-program national laboratories. The laboratory performs work in each of DOE's strategic goal areas: energy, national security, science, and the environment. Idaho National Laboratory is the nation's leading center for nuclear energy research and development. Day-to-day management and operation of the laboratory is the responsibility of Battelle Energy Alliance.

For more information, visit avt.inl.gov/evproject.shtml and avt.inl.gov/chargepoint.shtml.

\section{References}

${ }^{1}$ http://avt.inl.gov/pdf/EVProj/ResidentialControllableDeman dlnSanDiego.pdf.

${ }^{2}$ http://www.sdge.com/customer-choice/customerchoice/dynamic-load-profiles, accessed January 9, 2015.

${ }^{3}$ http://www.energy.ca.gov/drive/projects/ARV-09005.html5.

${ }^{4 "}$ Characterize the Demand and Energy Characteristics of Non-residential Alternating Current Level 2 Electric Vehicle Supply Equipment," http://avt.inl.gov/.

${ }^{5}$ http://regarchive.sdge.com/tm2/pdf/ELEC ELECSCHEDS TOU-A.pdf.

6"Do Plug-In Electric Vehicle Drivers Park near Publicly Accessible Electric Vehicle Supply Equipment in San Diego but Not Use Them?," http://avt.inl.gov/.

${ }^{7}$ http://avt.inl.gov/pdf/EVProj/ResChargingBehaviorlnRespo nseToExperimentalRates.pdf. 